MOL . 20060726.0018

Jason D. Pless, J. Benjamin Chwirka, James

L. KrumhansI

\title{
Iodine Sequestration Using Delafossites and Layered Hydroxides
}

Accepted: $\uparrow+\boldsymbol{\uparrow} /$ Published online: $\boldsymbol{+}+$

(C) Springer-Verlag 2006

Abstract 10.1007/s00410-002-0431-0

The objective of this document is to report on early success for sequestering ${ }^{129} \mathrm{I}$. Sorption coefficients $\left(K_{\mathrm{d}}\right)$ for $\mathrm{I}$ and $\mathrm{IO}_{3}{ }^{-}$onto delafossites, spinels and layered metal hydroxides were measured in order to compare their applicability for sequestering ${ }^{129} \mathrm{I}$. The studies were performed using a dilute fluid composition representative of groundwater indigenous to the Yucca mountain area. Delafossites generally exhibited relatively poor sorption coefficients $\left(<10^{1.7} \mathrm{~mL} / \mathrm{g}\right)$. In contrast, the composition of the layered hydroxides significantly affects their ability to sorb $\mathrm{I}$. $\mathrm{Cu} / \mathrm{Al}$ and $\mathrm{Cu} / \mathrm{Cr}$ layered hydroxide samples exhibit $K_{\mathrm{d}}$ 's greater than $10^{3} \mathrm{~mL} / \mathrm{g}$ for both $\mathrm{I}$ and $\mathrm{IO}_{3}$.

Keywords Iodide sequestration; iodate sequestration, hydrotalcites, delafossites

\section{Introduction}

A key element in fielding a high level nuclear waste repository at Yucca Mountain, Nevada is to demonstrate that dose rates at some distant point of compliance will not exceed regulatory limits through the use of performance assessment models. Implicit in this approach is the fact that the most mobile radionuclides present in natural groundwaters are likely to play a large role in determining the eventual performance of the proposed facility. Although radioactive wastes have large radioisotope inventories, the considerations of half life, relative abundance, solubility, and aqueous chemistry dictate that the chief elements of concern are $\mathrm{Tc}, \mathrm{Np}$, and $\mathrm{I}$.

Inorganic iodine exists in aqueous environments as I (aq), $\mathrm{IO}_{3}(\mathrm{aq})$ and $\mathrm{I}_{2}(\mathrm{aq})$ species and are exceptionally mobile. These solutes do not sorb strongly to mineral surfaces, because the mineral surfaces commonly possess negative surface charges which repel anions. Therefore, finding materials that prevent the migration of ${ }^{129} \mathrm{I}$ is desirable.

Sequestration of ${ }^{129} \mathrm{I}$ is not, at least formally, a very difficult

J.D. Pless, J.B. Chwirka, J.L. Krumhansl

Sandia National Laboratories, P.O. Box 5800, MS 0754, Albuquerque, NM, USA 87185-0754

jlkrumh@sandia.gov

Tel.: (505) 844 9093, Fax: (505) 8447354 problem. Ikeda et al. (1994) have demonstrated that cinnabar (HgS) has a strong affinity for I. However, the inclusion of large amounts of a mercury-containing material in a working environment is not environmentally tractable. Yet, the implicit chemistry suggests a list of potential iodide getters, including divalent and monovalent metals in the lower right portion of the periodic table.

Iodide sorption to other minerals is generally limited. Muramatsu et al. (1990) reported essentially no sorption of $\mathrm{I}^{*}$ from distilled water onto sandy quartz, bentonite, kaolinite or $\mathrm{Al}_{2} \mathrm{O}_{3}$. Ticknor and Cho (1990) did not observe sorption of $\mathrm{I}^{\circ}$ onto bentonite or granitic fracture-filling minerals (i.e. goethite, hematite, chlorite, etc.) using a synthetic groundwater dominated by $\mathrm{Ca}^{2+}, \mathrm{Na}^{+}$, and $\mathrm{Cl}^{-}$ions. Sazarashi et al. (1994) did not detect $I$ sorption to montmorillonite $\left(10^{-6} \mathrm{M} \mathrm{KI}\right.$ and a 5-day contact period). Ticknor et al. (1996) measured low Iadsorption coefficients $\left(K_{\mathrm{d}}\right.$ 's $<5 \mathrm{~mL} / \mathrm{g}$ ) for biotite, goethite, granite and montmorillonite when measured in a synthetic groundwater dominated by the $\mathrm{Ca}^{2+}, \mathrm{Na}^{+}, \mathrm{Cl}^{-}$, and $\mathrm{SO}_{4}{ }^{2 \cdot}$ ions.

In addition, the iodine oxidation state has a significant effect on the degree of sorption. Couture et al. (1983) reported that $>99.9 \%$ of the $\mathrm{IO}_{3}$ and only $30 \%$ of I was sorbed by hematite. They also reported that $>21 \%$ of the $\mathrm{IO}_{3}{ }^{\circ}$ and less than $5 \%$ of the I was sorbed onto kaolinite and that qualitatively $\mathrm{IO}_{3}{ }^{-}$was sorbed more strongly by freshly precipitated $\mathrm{Fe}(\mathrm{OH})_{3}$ than $\mathrm{I}$. Mauramatsu et al. (1990) reported that more $\mathrm{IO}_{3}^{-}$than $\mathrm{I}^{-}$was sorbed onto $\mathrm{Fe}_{2} \mathrm{O}_{3}$. Similarly, Ticknor and Cho (1990) observed that $\mathrm{IO}_{3}^{-}$was sorbed more readily than $\mathrm{I}^{-}$to granitic minerals. The difference in the sorptive behavior between $\mathrm{I}^{-}$and $\mathrm{IO}_{3}{ }^{-}$is unknown. Presumably the "harder" basic nature of $\mathrm{IO}_{3}^{-}$, as compared to $\mathrm{I}$, favors the "hard-hard" interactions with the "hard" acid sites on the mineral surfaces.

The objective of this study was to screen promising materials for use in the proposed Yucca Mountain waste repository from an extensive list of possibilities gleaned from past experience and the literature. Toward this end, the test matrix was limited to assessing only getter performance in a single dilute fluid composition representative of the indigenous groundwater. Further, only short term experiments (days) were performed, and no attempt was made to heat or dehydrate materials beyond what was inherent in their various synthetic processes. Two classes of materials were selected for study, hydrotalcites (because of their ability to engage in anion exchange processes), and delafossites (Balsley et al. (1998) had observed that copper had some affinity for $I$ ). 


\section{Experimental}

\section{Materials Synthesis and Characterization}

Seven polycrystalline delafossites and three compositionallyrelated spinels were synthesized by solid state reaction. Stoichiometric amounts of $\mathrm{Cu}_{2} \mathrm{O}$ (Alfa Aesar, 99.9\%), $\mathrm{CuO}$ (Alfa Aesar, 99.7\%), $\mathrm{Al}_{2} \mathrm{O}_{3}$ (Alfa Aesar, 99.9\%), $\mathrm{V}_{2} \mathrm{O}_{3}$ (Alfa Aesar 99.7\%), $\mathrm{Cr}_{2} \mathrm{O}_{3}$ (Alfa Aesar, 99\%), $\mathrm{Mn}_{2} \mathrm{O}_{3}$ (Alfa Aesar, 98\%), $\mathrm{Fe}_{2} \mathrm{O}_{3}$ (Alfa Aesar, 99.9\%), $\mathrm{Ga}_{2} \mathrm{O}_{3}$ (Alfa Aesar, 99.99\%), and $\mathrm{Y}_{2} \mathrm{O}_{3}$ (Alfa Aesar, 99.9\%) were ground with an agate mortar and pestle. The delafossites and spinels were calcined in flowing $\mathrm{N}_{2}$ and air, respectively, between $750-1100{ }^{\circ} \mathrm{C}$ for 24 $h$. The materials were ground to a fine powder.

Nineteen polycrystalline hydrotalcites (HTCs) were synthesized by direct co-precipitation of the divalent and trivalent cations at room temperature. Stoichiometric amounts of $\mathrm{Mg}\left(\mathrm{NO}_{3}\right)_{2} \cdot 6 \mathrm{H}_{2} \mathrm{O}$ (Alfa Aesar, 98\%), $\mathrm{Co}\left(\mathrm{NO}_{3}\right)_{2} \cdot 6 \mathrm{H}_{2} \mathrm{O}$ (Aldrich, 98\%), $\mathrm{Ni}\left(\mathrm{NO}_{3}\right)_{2} \cdot 6 \mathrm{H}_{2} \mathrm{O}$ (Aldrich, 98.5\%), $\mathrm{Cu}\left(\mathrm{NO}_{3}\right)_{2}$. $2.5 \mathrm{H}_{2} \mathrm{O}$ (Aldrich, 98\%), $\mathrm{Zn}\left(\mathrm{NO}_{3}\right)_{2} \cdot 6 \mathrm{H}_{2} \mathrm{O}$ (Aldrich, 99\%), $\mathrm{Pd}\left(\mathrm{NO}_{3}\right)_{2}$ solution (Alfa Aesar, Pd 8.5\% w/w) or $\mathrm{Cd}\left(\mathrm{NO}_{3}\right)_{2} \cdot 4$ $\mathrm{H}_{2} \mathrm{O}$ (Alfa Aesar, 98\%) and $\mathrm{Al}\left(\mathrm{NO}_{3}\right)_{3} \cdot 9 \mathrm{H}_{2} \mathrm{O}$ (Alfa Aesar, 98\%), $\mathrm{Cr}\left(\mathrm{NO}_{3}\right)_{3} \cdot 9 \mathrm{H}_{2} \mathrm{O}$ (Aldrich, 99\%), $\mathrm{Fe}\left(\mathrm{NO}_{3}\right)_{3} \cdot 6 \mathrm{H}_{2} \mathrm{O}$ (Aldrich, 98\%), $\mathrm{Ga}\left(\mathrm{NO}_{3}\right)_{3} \cdot \mathrm{X} \mathrm{H}_{2} \mathrm{O}$ (Alfa Aesar, 99.9\%), or $\mathrm{La}\left(\mathrm{NO}_{3}\right)_{3} \cdot 6 \mathrm{H}_{2} \mathrm{O}$ (Alfa Aesar, 99\%) were dissolved in $400 \mathrm{~mL}$ of DI water. The $\mathrm{pH}$ of the solution was adjusted to $\sim 10$ with $\mathrm{NH}_{4} \mathrm{OH}$ (Fisher, Reagent), precipitating HTCs' and turning the solutions into a thick opaque suspensions. These mixtures aged for approximately 24 hours at room temperature. Then the product was filtered and washed until the conductivity of the filtrate was approximately 100 microsiemens. The product was dried overnight in air at $100{ }^{\circ} \mathrm{C}$ and then ground into a fine powder. Select samples were calcined at $550^{\circ} \mathrm{C}$ between 1 and 24 hours.

The samples' structures were identified using powder X-ray diffraction (XRD). The XRD patterns were recorded at room temperature on a Siemens Kristalloflex D 500 diffractometer (Cu K $\alpha$ radiation, Kevex detector, $40 \mathrm{kV}, 30 \mathrm{~mA}$; 5-60 $2 \theta$, $0.05^{\circ}$ step size and $3 \mathrm{~s}$ count time). The phases were identified by comparison with the data reported in the JCPDS (Joint Committee of Powder Diffraction Standards) database.

\section{Simulant Solution}

The fluid used in these experiments was based on the composition of a standard Yucca Mountain Project groundwater, "J-13" (Rosenberg et al., 2001), though the recipe was slightly modified to avoid a preparation that involved adding calcite or fluorite - both of which could presumably take decades to dissolve completely.

\section{Sorption Studies}

Sorption experiments were conducted by equilibrating sequestration materials with aliquots of simulated test fluid spiked with $1 \mathrm{ppm}$ of (non-radioactive) ${ }^{127} \mathrm{~T}$ or ${ }^{127} \mathrm{IO}_{3}$. Solutionto-solid ratios $(\mathrm{mL} / \mathrm{g})$ of $\sim 100(250 \mathrm{mg}$ of sequestration material in $25 \mathrm{~mL}$ of spiked solution) were used to evaluate the degree of radionuclide loading on the sorbents. A positive control containing the I spiked simulant solution and no material was used to evaluate the I sorption to the labware. The mixture was gently agitated for $\sim 24 \mathrm{~h}$ at $25 \pm 3{ }^{\circ} \mathrm{C}$.
Analysis of $I$ in the liquid samples depended upon the analyte. The iodide concentration was measured with a specific ion electrode. The iodate concentration was determined using inductively coupled plasma - mass spectroscopy (ICP-MS). The $K_{\mathrm{d}}$ values were calculate using the following formula:

$$
K_{\mathrm{d}}(\mathrm{mL} / \mathrm{g})=\left\{\left[\mathrm{A}_{\mathrm{ix}}\right] / \mathrm{g}_{\mathrm{ix}}\right\} /\left\{\left[\mathrm{A}_{\mathrm{sin}}\right] / \mathrm{mL}_{\mathrm{sln}}\right\}
$$

where $\left[A_{i x}\right]$ is the concentration decrease arising from "sorption", $g_{i x}$ is the mass of the sorbent, $\left[A_{s \mid \mathrm{n}}\right]$ is the iodine concentration in solution, $\mathrm{mL}_{\mathrm{sin}}$ is the volume of solution.

\section{Results and discussion}

The following sections review the performances of the different classes of materials as they were assessed by what is commonly referred to as batch "sorption" tests; mechanistic insights are not necessarily implicit in data obtained in this manner. The tests were intended to provide a cost-effective method for differentiating between getters with relatively poor performance and those with potential for iodine sequestration in an environment that is superficially relevant to a subset of the proposed Yucca Mountain repository environments. Further, the experiments were designed so that the iodine would never be a major component in the test fluid. Consequently, if a normal groundwater solute interferes with iodine sequestration (without presuming any particular sorption mechanism), then the empirical result suggests that the getter is a poor performer. Preliminary results suggest that a rough metric for a successful sequestration material (e.g., one that could impact the dose at the point of compliance) is that it will have an adsorption coefficient $\left(K_{\mathrm{d}}\right)$ greater than $10^{3}$ (MacNeil et al., 1999).

\section{Delafossites and Spinels}

The delafossite structure is of interest as an iodine scavenger because it contains monovalent copper in a two-coordinate environment. Delafossites have the general chemical formula $\mathrm{ABO}_{2}$ and can be described as alternating layers of edge-shared $\mathrm{BO}_{6}$ octahedra and two-coordinate noble metal A-site cations. This structure type can accommodate various monovalent $A$-site cations $(\mathrm{Cu}, \mathrm{Pd}, \mathrm{Pt}$ and $\mathrm{Ag})$ and trivalent $\mathrm{B}$-site cations $(0.53<$ $r\left(\right.$ six coordinate $\left.\left.\mathrm{B}^{3+}\right)<1.09 \AA\right)$. Select compositions were oxidized due to the uncertainty of the type of oxidizing/reducing atmosphere inside the repository. This treatment transformed the structure of the oxidized materials to spinel-like and increased the copper valence to +2 . The spinel structure can be described as layers of close-packed oxygen atoms with tetrahedral copper and octahedral tri-valent cations $\left(\mathrm{M}^{3+}\right)$.

The physical properties and sorption coefficients of the delafossites and spinels are summarized in Table 1. The sorption capacities of the delafossites and spinels are relatively small. Most of the iodide $\log \left(K_{\mathrm{d}}\right)$ values fall between 1 and 1.5. This has been observed in several other mineral systems (Couture et al. 1983, Mauramatsu et al. 1990, and Ticknor and Cho 1990). Interestingly, the iodate sorption coefficients of the delafossites are similar to those of iodide, but the iodate $K_{\mathrm{d}}$ values of the spinel-like compounds become significantly smaller. The difference might be related to the local structure of the copper. The copper in delafossite is relatively accessible with only two bonds to oxygen, whereas the copper in the spinel 
is bound to four oxygen atoms. Thus, it is more difficult for the larger $\mathrm{IO}_{3}$ anion to coordinate/bond to the copper in the spinel.

Table 1. Physical Properties and Sorption Coefficients of the Delafossites and Spinel Compounds ${ }^{a}$

\begin{tabular}{llccc}
\hline Composition & $\begin{array}{c}\text { Structure } \\
\text { Type }\end{array}$ & $\begin{array}{c}\text { Calcination } \\
\text { Temp. }\left({ }^{\circ} \mathrm{C}\right)\end{array}$ & $\begin{array}{c}\log K_{\mathrm{d}} \\
\mathrm{I}\end{array}$ & $\begin{array}{c}\log K_{\mathrm{d}} \\
\mathrm{IO}_{3}^{-}\end{array}$ \\
\hline $\mathrm{CuAlO}_{2}$ & Delafossite & 1090 & 1.5 & $<1.40$ \\
$\mathrm{CuCrO}_{2}$ & Delafossite & 1000 & 0.54 & 1.64 \\
$\mathrm{CuMnO}_{2}$ & Delafossite & 960 & $<1$ & $<1.40$ \\
$\mathrm{CuFeO}_{2}$ & Delafossite & 1050 & 1.5 & $<1.40$ \\
$\mathrm{CuFe}_{2} \mathrm{O}_{4}$ & Spinel & 750 & 0.99 & 0.00 \\
$\mathrm{CuGaO}_{2}$ & Delafossite & 1070 & 1.3 & $<1.40$ \\
$\mathrm{CuYO}_{2}$ & Delafossite & 1050 & 1.49 & 1.48 \\
$\mathrm{CuY}_{2} \mathrm{O}_{5}$ & Spinel & 1050 & 1.04 & 0.27 \\
$\mathrm{CuV}_{0,5} \mathrm{Fe}_{0,5} \mathrm{O}_{2}$ & Delafossite & 850 & - & $<1.40$ \\
\hline
\end{tabular}

a. Dash (-) indicates no test was performed.

\section{Hydrotalcites}

Hydrotalcites (HTCs), with general formula $\left[\mathrm{M}^{(\mathrm{II})}{ }_{\text {. }}\right.$. $\left.{ }_{x} \mathrm{M}^{(11)}(\mathrm{OH})_{2}\right]^{\mathrm{x+}}[\mathrm{A}] \cdot \mathrm{mH}_{2} \mathrm{O}$ where $\mathrm{M}^{(1 \mathrm{II)}}=\mathrm{Mg}^{2+}, \mathrm{Ca}^{2+}, \mathrm{Mn}^{2+}, \mathrm{Fe}^{2+}$, $\mathrm{Co}^{2+}, \mathrm{Ni}^{2+}, \mathrm{Zn}^{2+}$; and $\mathrm{M}^{(\mathrm{III})}=\mathrm{Al}^{3+}, \mathrm{Cr}^{3+}, \mathrm{Mn}^{3+}, \mathrm{Fe}^{3+}, \mathrm{Co}^{3+}$, and $\mathrm{Ga}^{3+}$; $\mathrm{A}=\mathrm{Cl}^{-}, \mathrm{Br}, \mathrm{I}, \mathrm{NO}_{3}^{-}, \mathrm{CO}_{3}{ }^{2-}, \mathrm{SO}_{4}^{2-}$, silicate-, polyoxometalate and/or organic ions, are well known for their ion exchange abilities (Miyata 1975). The crystal structure of hydrotalcite can be described as positively charged layers of $\left[\mathrm{M}^{(\mathrm{III})} / \mathrm{M}^{(\mathrm{III})} /(\mathrm{OH})\right]$ octahedra. The net positive charge is compensated for by anions located between the layers. Ion exchange in hydrotalcites occurs via two routes: 1) the classic ion exchange process and 2) the so-called "memory affect". In the classical ion exchange method, the A-HTC is dispersed in an aqueous solution containing a second anion. The $A^{\prime}$, and $A^{\prime}$ anions partially substitute for $A$, forming $A_{x} A^{\prime}{ }_{1-x}-H T C$. In the "memory affect" method, the HTC is calcined and the structure collapses due to anion and water loss. The collapsed material is dispersed into an aqueous solution containing an ion and the HTC structure recrystallizes including the "new" ion.

The physical properties and sorption coefficients of the layered metal hydroxides are summarized in Table 2. Although the layered metal hydroxides in Table 2 are of diverse composition, the samples were found by X-ray diffraction to exhibit a characteristic low angle feature indicating they all have a layered structure characteristic of a hydrotalcite. The sorption coefficients $\left(\log K_{\mathrm{d}}\right.$ ) for iodide fall in a rather large range, from $10^{1}-10^{4}$. Similar results were observed for $\mathrm{Zn} / \mathrm{Al}$ HTC by Balsley et al. (1998). The iodide sorption does not appear to be significantly affected by the identity of the trivalent cation, except for $\mathrm{La}^{3+}$. This is not surprising as the ionic radius of six-coordinate lanthanum (1.032 $\AA$ ) is significantly larger than those of six-coordinate aluminum, chromium, iron and gallium (0.535 $\AA, 0.615 \AA, 0.645 \AA$, and $0.620 \AA$, respectively). This might cause structural distortions of the octahedral layer, negatively affecting the bonding of $\mathrm{I}$. Samples containing $\mathrm{Cu}^{2+}$ exhibited the highest sorption for iodide, followed by the samples containing $\mathrm{Co}^{2+}$ and $\mathrm{Ni}^{2+}$. These three metals are classified as "border region" elements of the hard/soft acceptor properties. The difference in sorption capacity between these three elements could be due to their electronic structures and/or a layered metal hydroxide with Jahn-Teller distortions exhibited by $\mathrm{Cu}^{2+}$. It was thought that the soft acceptor, $\mathrm{Pd}^{2+}$, would exhibit a higher iodide sorption capacity than the analogous $\mathrm{Ni}^{2+}$ compound, however, the sorption capacity of the palladium structure was about an order of magnitude smaller. Again, this might be due to structural distortions of the octahedral layer caused by the larger ionic radius of six-coordinate $\operatorname{Pd}^{2+}(0.86 \AA)$ compared to $\mathrm{Ni}^{2+}(0.690 \AA)$.

Table 2. Physical Properties and Sorption Coefficients of the Layered Metal Hydroxides ${ }^{a}$

\begin{tabular}{|c|c|c|c|}
\hline Composition & $\begin{array}{c}\text { Structure } \\
\text { Type }^{b}\end{array}$ & $\log K_{\mathrm{d}} \mathrm{I}^{-}$ & $\log K_{\mathrm{d}} \mathrm{IO}_{3}$ \\
\hline $\mathrm{Mg}_{6} \mathrm{Al}_{2}(\mathrm{OH})_{18}$ & HTC & 1.60 & 0.52 \\
\hline $\mathrm{Co}_{6} \mathrm{Al}_{2}(\mathrm{OH})_{18}$ & HTC & 2.36 & 4.00 \\
\hline $\mathrm{Ni}_{6} \mathrm{Al}_{2}(\mathrm{OH})_{18}$ & HTC & 2.51 & 4.70 \\
\hline $\mathrm{Cu}_{6} \mathrm{Al}_{2}(\mathrm{OH})_{18}$ & HTC & 3.98 & $>4.66$ \\
\hline $\mathrm{Zn}_{6} \mathrm{Al}_{2}(\mathrm{OH})_{18}$ & HTC & 2.26 & 3.82 \\
\hline $\mathrm{Pd}_{6} \mathrm{Al}_{2}(\mathrm{OH})_{18}$ & HTC & 1.55 & 1.93 \\
\hline $\mathrm{Cd}_{6} \mathrm{Al}_{2}(\mathrm{OH})_{18}$ & HTC & 1.20 & - \\
\hline $\mathrm{Co}_{6} \mathrm{Cr}_{2}(\mathrm{OH})_{18}$ & HTC & 1.99 & 4.51 \\
\hline $\mathrm{Ni}_{6} \mathrm{Cr}_{2}(\mathrm{OH})_{18}$ & HTC & 2.63 & $>4.66$ \\
\hline $\mathrm{Cu}_{6} \mathrm{Cr}_{2}(\mathrm{OH})_{18}$ & HTC & 3.62 & $>4.66$ \\
\hline $\mathrm{Co}_{6} \mathrm{Fe}_{2}(\mathrm{OH})_{18}$ & HTC & 1.53 & 3.89 \\
\hline $\mathrm{Ni}_{6} \mathrm{Fe}_{2}(\mathrm{OH})_{18}$ & HTC & 2.15 & 4.78 \\
\hline $\mathrm{Cu}_{6} \mathrm{Fe}_{2}(\mathrm{OH})_{18}$ & $\mathrm{CHN}$ & 2.89 & 4.22 \\
\hline $\mathrm{Ni}_{6} \mathrm{Ga}_{2}(\mathrm{OH})_{18}$ & HTC & 2.02 & 3.79 \\
\hline $\mathrm{Cu}_{6} \mathrm{Ga}_{2}(\mathrm{OH})_{18}$ & $\mathrm{CHN}$ & 3.22 & 4.72 \\
\hline $\mathrm{Zn}_{6} \mathrm{Ga}_{2}(\mathrm{OH})_{18}$ & HTC & 1.36 & 3.19 \\
\hline $\mathrm{Co}_{6} \mathrm{La}_{2}(\mathrm{OH})_{18}$ & HTC & 1.82 & 2.66 \\
\hline $\mathrm{Ni}_{6} \mathrm{La}_{2}(\mathrm{OH})_{18}$ & HTC & 1.83 & 3.17 \\
\hline $\mathrm{Cu}_{6} \mathrm{La}_{2}(\mathrm{OH})_{88}$ & $\mathrm{CHN}$ & 1.62 & 1.77 \\
\hline
\end{tabular}

Nearly all of the layered metal hydroxides' sorption capacities were larger for $\mathrm{IO}_{3}^{-}$than for iodide, except for the $\mathrm{Mg} / \mathrm{Al}$ - HTC. Interestingly, the iodate sorption values for all but four layered metal hydroxides (Mg/Al, $\mathrm{Pd} / \mathrm{Al}, \mathrm{Co} / \mathrm{La}$ and $\mathrm{Cu} / \mathrm{La})$ were $10^{3}$ or higher. The sorption capacities followed the same trends for iodate as for iodide. Several of the Co-, Ni- and $\mathrm{Cu}$ - HTCs exhibited $\mathrm{I}^{-}$and $\mathrm{IO}_{3}^{-}$sorption capacities greater than $10^{2}$.

Select compositions were calcined because of the uncertainty of the temperature inside the proposed repository. The calcination times and sorption properties of the selected calcined HTCs are listed in Table 3. It can be seen that the sorption capacities decreased for all of the anions after calcination. The length of calcination does not affect greatly the sorption values. The decrease in sorption capacities of the collapsed hydrotalcites is significant because more material would be required for the proposed repository than for samples with the layered metal hydroxide structure.

Table 3. Physical Properties and Sorption Coefficients of the Calcined Hydrotalcites ${ }^{n}$

\begin{tabular}{|c|c|c|c|}
\hline Composition & $\begin{array}{c}\text { Calcination } \\
\text { Time }\end{array}$ & $\log K_{d} I^{-}$ & $\log \mathrm{K}_{\mathrm{d}} \mathrm{IO}_{3}$ \\
\hline $\mathrm{Ni}_{6} \mathrm{Al}_{2}(\mathrm{OH})_{18}$ & 1 hour & - & 1.99 \\
\hline $\mathrm{Ni}_{6} \mathrm{Al}_{2}(\mathrm{OH})_{18}$ & 24 hours & 1.56 & 1.93 \\
\hline $\mathrm{Ni}_{6} \mathrm{Ga}_{2}(\mathrm{OH})_{1 \mathrm{R}}$ & 1 hour & 0.89 & 2.42 \\
\hline
\end{tabular}




\begin{tabular}{lccc}
\hline $\mathrm{Ni}_{6} \mathrm{Ga}_{2}(\mathrm{OH})_{18}$ & 24 hours & 1.33 & 1.92 \\
$\mathrm{Zn}_{6} \mathrm{Ga}_{2}(\mathrm{OH})_{18}$ & 1 hour & 1.36 & - \\
$\mathrm{Zn}_{6} \mathrm{Ga}_{2}(\mathrm{OH})_{18}$ & 22 hours & 1.04 & - \\
\hline
\end{tabular}

a. Dash (-) indicates no test was performed.

The layered metal hydroxides offer promise for sequestering ${ }^{129} \mathrm{I}$ anions. Two HTC samples $(\mathrm{Cu} / \mathrm{Al}$ and $\mathrm{Cu} / \mathrm{Cr}$ ) exhibited sorption capacities of $10^{3}$ or greater for iodide and iodate. It cannot be emphasized enough that the data reported here are not intended to provide the scope needed to assess getter performance under in-situ repository conditions. A more elaborate testing protocol is required before it is possible to certify a material for use under the full range of potential conditions that might arise in the facility. Further studies are needed to determine the affects of composition, particle properties, radiation damage, the time the HTC is in the stimulant solution, the composition of the stimulant solution, etc. on the ability of these materials to sorb radioactive anions.

\section{Conclusion}

Delaffosites and layered hydroxides were studied to determine their ability to sorb ${ }^{129} I$. Sorption studies, using a dilute fluid composition representative of groundwater indigenous to the Yucca mountain area, indicate that delafossites are relatively poor for sequestering ${ }^{129} \mathrm{I}$ species. However, layered metal hydroxides exhibit significant sorption for iodide and iodate. It is shown that the composition of the layered hydroxides significantly affects the ability to sorb iodine. $\mathrm{Cu} / \mathrm{Al}$ and $\mathrm{Cu} / \mathrm{Cr}$ layered hydroxide samples exhibit $K_{\mathrm{d}}$ 's greater than $10^{3} \mathrm{~mL} / \mathrm{g}$ for both $\mathrm{I}$ and $\mathrm{IO}_{3}$. Calcination of the hydrotalcites significantly decreases their ability to sorb $\mathrm{I}$ and $\mathrm{IO}_{3}$.

\section{Acknowledgements}

The authors thank R. Bontchev, K. Helean and K. Holt for helpful discussions. Sandia is a multiprogram laboratory operated by Sandia Corporation, a Lockheed Martin Company, for the United States Department of Energy's National Nuclear Security Administration under contract DE-AC04-94AL85000.

\section{References}

Balsley SD, Brady PV, Krumhansl JL, Anderson HL (1998) Anion scavengers for low-level radioactive waste respository backfills, J Soil Contamination 7: 125-141

Couture RA, Seitz, MG (1983) Sorption of anions of iodine by iron-oxides and kaolinite, Nucl Chem Waste Management 4: 301-306

Ikeda Y, Sazarashi M, Tsuji M, Seki R, Yoshikawa H (1994) Adorption of I- ions on cinnabar for I-129 waste management, Radiochim Acta 31: 195-198

MacNeil K, Thiers TG, Zarrabi K, McKenzie DG, Saudners RS (1999) Diffusive barrier and getter under waster packages VA Reference Design .Feature Evaluations, B00000000-
0717-2200-00213 Revision 00(c), MOL 199902525,0399, YMP program design document.

Muramatsu Y, Uchida S, Sriyotha P, Sriyotha K (1990) Some considerations on the sorption and desorption phenomena of iodide and iodate on soil, Water Air Soil Pollut 49: 125-138 DOI 10.1007/BF00279516

Miyata S (1975) Syntheses of hydrotalcite-like compounds and their structures and physiochemical properties. I. Systems $\mathrm{Mg}^{2+}-\mathrm{Al}^{3+}-\mathrm{NO}_{3}, \mathrm{Mg}^{2+}-\mathrm{Al}^{3+}-\mathrm{Cl}^{2}, \mathrm{Mg}^{2+}-\mathrm{Al}^{3+}-\mathrm{ClO}_{4} ; \mathrm{Ni}^{2+}-\mathrm{Al}^{3+}-\mathrm{Cl}$ and $\mathrm{Zn}^{2+}-\mathrm{Al}^{3+}-\mathrm{Cl}$, Clays Clay Miner 23: 369

Rosenberg ND, Gdowski GE, Knauss KG (2001) Evaporative chemical evolution of natural waters at Yucca Mountain, Appl Geochem 16: 2131-1240.

Sazarashi M, Ikeda Y, Seki R, Yoshikawa H (1994) Adsoprtion of I- ions on minerals for I-129 waste management, J Nucl Sci Technol 31: 620-622.

Ticknor KV, Cho YH (1990) Interaction of iodide and iodate with granitic fracture-filling minerals, J Radioanal Nucl Chem 140: 75-90 DOI 10.1007/BF02037365

Ticknor KV, Vilks P, Vandergraaf TT (1996) The effect of fulvic acid on the sorption of actinides and fission products on granite and selected minerals, Appl Geochem 11: 555565 . 